\title{
Effect of naloxone on food competition aggression in food-restricted high and low aggression pigeons (Columba livia)
}

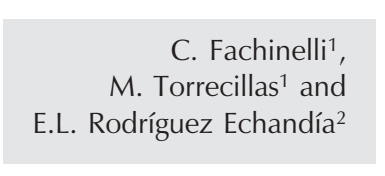

Correspondence

E.L.R. Echandía

Casilla de Correo 33

5500-Mendoza

Argentina

E-mail: erech@fmed2.uncu.edu.ar

Research supported by the Consejo Nacional de Investigaciones Científicas y Técnicas of Argentina (CONICET, PIP 4682/96) and by the Aconcagua University and National University of Cuyo, Mendoza, Argentina.

....................

Received February 4, 2003 Accepted November 4, 2003

\author{
${ }^{1}$ Laboratorio de Psicología Experimental y Comparada, \\ Universidad del Aconcagua and INCIHUSA (CRICYT), Mendoza, Argentina \\ ${ }^{2}$ Unidad de Neuroquímica y Farmacología del Comportamiento (UNEFCO-IMBECU), \\ CONICET, Facultad de Ciencias Médicas, Universidad Nacional de Cuyo, Mendoza, \\ Argentina
}

\begin{abstract}
We determined the effect of the opiate receptor antagonist naloxone on aggression, emotion, feeder control, and eating behavior in high and low aggression female pigeons maintained at $80 \%$ of their normal weight and exposed to food competition interactions. Pigeons were divided into pairs by previously ranked high aggression (total time spent in offensive aggression exceeding $60 \mathrm{~s} / 5 \mathrm{~min} ; \mathrm{N}=6$ pairs) and low aggression females (time spent in offensive aggression less than $10 \mathrm{~s} / 5 \mathrm{~min} ; \mathrm{N}=6$ pairs). A pigeon in each pair received an $s c$ dose of naloxone $\left(1 \mathrm{mg} \mathrm{kg}^{-1} \mathrm{ml}\right.$ saline-1) and the other animal received the vehicle. Trials $(10 \mathrm{~min})$ were performed $30 \mathrm{~min}$ after the naloxone/ vehicle administration. The naloxone group of high aggression pigeons showed lower scores of total time spent in offensive aggression (control: $98.6 \pm 12.0$; naloxone: $46.8 \pm 6.6 \mathrm{~s} ; \mathrm{P}<0.05$ ) and higher scores of time spent in emotional responses (control: $3.5 \pm 0.6$; naloxone: $10.8 \pm 2.4 \mathrm{~s} ; \mathrm{P}<0.05$ ) than controls. The other behaviors scored, feeder control and eating behavior, were not affected in this group. The naloxone group of low aggression pigeons, however, showed higher scores of offensive aggression than their controls (5.3 \pm 1.3 ; naloxone: $28.7 \pm 8.0 \mathrm{~s} ; \mathrm{P}<0.05$ ). The present results suggest that opiate receptor mechanisms are implicated in offensive aggression responses in high and low aggression pigeons. However, as reported for brain 5-hydroxytryptamine manipulation and GABA-A-benzodiazepine receptor manipulation, the effect of the opiate receptor antagonist on food competition aggression in pigeons was related to their pretreatment level of aggression.
\end{abstract} Key words - Naloxone - Aggressive behavior - Emotional behavior - Food competition - Pigeons

The food competition interaction test performed with food-restricted pigeons is a useful model for the study of social aggression. Using this test we have reported that the behavioral responses of pigeons to brain 5hydroxytryptamine (5-HT) and GABA-Abenzodiazepine (BZD) receptor manipula- tions are related to the natural aggressiveness they exhibit prior to the treatments. Either acute or chronic treatments with the 5HT precursor selectively blocked food competition aggression in high aggression pigeons $(1,2)$, while 5-HT depletion by intracerebroventricular injection of 5,7-di-hy- 
droxytryptamine (5,7-DHT) increased aggression selectively in low aggression pigeons (3). Subchronic treatment (seven days) with oral doses of diazepam (DZP) inhibits offensive aggression and emotional responses in high aggression pigeons, but causes a significant increase in the scores of offensive aggression in low aggression pigeons (4).

Opiate receptor antagonists have been used to treat various psychopathologies involving aggression in children and adolescents (5). It was reported that naloxone at doses that do not significantly affect behavior can reverse disinhibitory/aggressive behavior in 5,7-DHT-lesioned rats (6). The effect of the analogue naltrexone on agonistic confrontations also depends on a neurochemical background, differing between winner and loser mice (7). The offensive behavior response of high and low aggression pigeons to opiate receptor antagonists has not been reported.

The aim of the present study was to examine the effects of acute naloxone treatment on the offensive aggression and emotional responses of food-restricted high and low aggression pigeons exposed to food competition interactions.

Mature female domestic pigeons $(\mathrm{Co}-$ lumba livia) maintained at $80 \%$ of basal weight (food-restricted) were reared singly in $50 \times 40 \times 40 \mathrm{~cm}$ cages that were visually isolated from one another, in an animal room kept at constant temperature $\left(24 \pm 3^{\circ} \mathrm{C}\right)$ and lighting (lights on from 8:00 to 19:00 h). Each animal was ranked daily in an interaction cage for six consecutive days in the presence of another bird which was changed every day. The interaction cage measured $2.0 \times 2.0$ (base) $\times 2.0$ (height) $\mathrm{m}$. The front wall had a $1.35 \times 0.41 \mathrm{~m}$ window provided with a dark glass allowing direct observation

Table 1. Structure of the behaviors selected for observation.

Offensive behavior: time spent ( $\mathrm{s} / 10 \mathrm{~min}$ ) in agonistic interactions involving a real or potential risk to the opponent pigeon:

- pursuing: to follow in order to attack or chase away the opponent.

- hooking: to attack with a wing to hold the opponent.

- pecking: to hold with the beak preventing opponent's access to food, or in areas far from food, after chasing (to follow quickly in order to harm).

- wingbeating: to hit with the wings.

- aggressive vocalization: vocalizations close to feeder or in areas far from food, together with horizontal movements of head and body causing wing tremor or running away in the opponent.

- threatening: to express intention to inflict injury causing immobility or running away in the opponent.

Emotional behavior: time spent (s/10 min) in behaviors involving fear and anxiety responses following offensive acts of the opponent.

- watching: close observation of the opponent for a time.

- wing tremor: after an attack or aggressive vocalizations by the opponent.

- fear vocalizations: short vocalizations accompanied by expiration and immobility after an aggressive attack by the opponent.

- immobility: freezing-like behavior in a corner of the interaction cage (far from the feeder).

- intent to leave the observation chamber (flying up to the top of the chamber)

Feeder control behavior (standard laboratory measure of dominance): time spent (s/10 min) in: - eating attempts: raising and lowering the head at the feeder without eating.

- pushing the opponent away from the feeder.

- wing covering the feeder.

- walking around the feeder.

- immobility close to the feeder.

Eating behavior: time spent (s/10 $\mathrm{min})$ in:

- eating at the feeder.

- eating out of the feeder (food from the feeder spilled on the surrounding floor). 
of animal behavior without visual disturbance. To induce fighting a feeder (a $25-\mathrm{cm}$ high pyramid) was placed at the center of the arena. The feeder had a short arm bearing a single $2.0-\mathrm{cm}$ hole through which just one bird could freely eat a mixture of grains. All agonistic interactions involving a real or potential risk to the opponent pigeon were considered to be offensive behavior (see Table 1). Females showing a mean time spent in offensive aggression exceeding $60 \mathrm{~s} / 5 \mathrm{~min}$ over the six test sessions were arbitrarily ranked as "high aggression subjects" $(\mathrm{N}=$ 12). Pigeons with the shortest offensive aggression time (less than $10 \mathrm{~s} / 5 \mathrm{~min}$ ) were ranked as "low aggression subjects" $(\mathrm{N}=$ 12). A total of 12 pairs with similar aggression scores were obtained.

In preliminary dose-response experiments we found that $0.5 \mathrm{mg} / \mathrm{kg}$ naloxone (sc) had no behavioral effects in the food competition test. Doses of 1 and $1.5 \mathrm{mg} / \mathrm{kg}$ affected aggressive responses without impairing general pigeon performance. Higher doses (2 $\mathrm{mg} / \mathrm{kg}$ ) impaired general behavior. In this experiment, one pigeon in each pair of high aggression ( $\mathrm{N}=6$ pairs) and low aggression subjects $(\mathrm{N}=6$ pairs $)$ was injected $s c$ with 1 $\mathrm{mg} / \mathrm{kg}$ naloxone dissolved in saline $(1 \mathrm{ml})$. The other member of the pair received $1 \mathrm{ml}$ saline. The food competition trials (10 min) were performed $30 \mathrm{~min}$ after naloxone administration. The duration of aggressive responses has been reported to be a highly reliable method of measuring aggression (8). The time (s) during which the animals exhibited offensive behavior, emotional behavior, feeder control behavior, and eating behavior (the main motivations of aggression) was measured by an observer who was blind to the treatment conditions. Times were recorded on a PC using software designed by us. The specific behaviors recorded for each category are listed in Table 1. As reported elsewhere (1-4), offensive aggression is reported as a) total time spent $/ 10 \mathrm{~min}$ in all forms of these behaviors, and b) structure of the aggressive behavior (time spent in each component of this behavior). The other behavioral categories are reported as total time spent. Comparisons between the mean behavioral scores of experimental (drug treated) animals and their controls in each experiment were analyzed by the Student $t$-test. Results are reported as means \pm SEM.

Figure 1 shows that the scores of total time spent in offensive aggression for the naloxone and control groups of high aggression females were significantly lower in the naloxone group $(\mathrm{P}<0.05)$. Analysis of the structure of offensive behavior showed significantly lower scores of pecking (control: $28.8 \pm 5.6$ vs naloxone: $11.3 \pm 3.5 \mathrm{~s} / 10 \mathrm{~min} ; \mathrm{P}<0.05)$ and hooking (control: $47.5 \pm 6.2 v s$ naloxone: $7.2 \pm 1.7 \mathrm{~s} /$ $10 \mathrm{~min} ; \mathrm{P}<0.05)$ and only a trend toward lower scores of threatening and aggressive vocalizations (results not shown).

The differences in the scores of total time spent in offensive aggression between the naloxone and control groups of low aggression females were also significant $(\mathrm{P}<0.05)$. However, this was due to the higher scores of offensive aggression for the naloxone group (Figure 1). Analysis of the structure of offensive behavior showed a significant increase in pecking scores (control: $2.33 \pm 0.5$ vs naloxone: $10.8 \pm 2.4 \mathrm{~s} / 10 \mathrm{~min} ; \mathrm{P}<0.05$ ) and only a trend toward higher threatening and hooking scores (results not shown).

In the high aggression pigeons naloxone increased the total time spent in emotional responses (control: $3.5 \pm 0.6$ vs naloxone: $12.8 \pm 1.3 \mathrm{~s} / 10 \mathrm{~min} ; \mathrm{P}<0.05)$. The total time

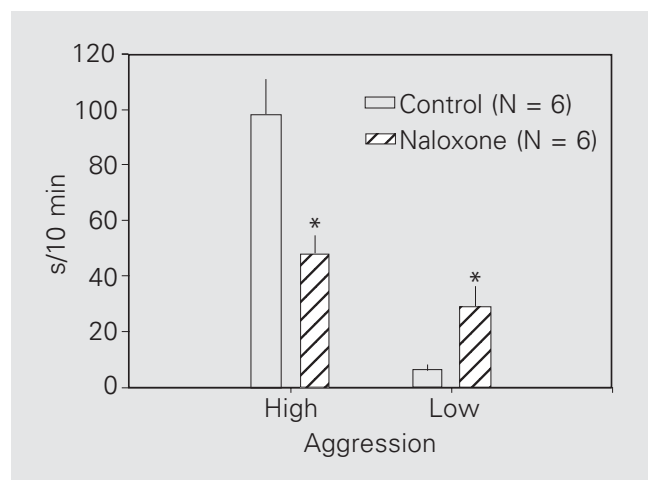

Figure 1. Effects of naloxone (1 $\mathrm{mg} / \mathrm{kg}$ ) on total time spent in offensive aggression by high and low aggression pigeons. Data are reported as means \pm SEM. High = high aggression; Low = low aggression. ${ }^{*} \mathrm{P}<0.05$ vs control scores (Student $t$-test). 
spent in emotional behavior was very low in the control group of low aggression pigeons and naloxone caused only a trend toward lower emotional responses (control: $1.9 \pm$ $0.3 v s$ naloxone: $1.0 \pm 0.2 \mathrm{~s} / 10 \mathrm{~min})$. The other behaviors scored (feeder control and eating behavior) were not changed by naloxone in high or low aggression females (results not shown).

The present results show that an $s c$ injection of naloxone $(1 \mathrm{mg} / \mathrm{kg})$ clearly decreased offensive aggression in the food-restricted high aggression pigeons exposed to food competition interactions. The treatment significantly reduced two of the main components of offensive aggression (pecking and hooking). Since their emotional scores were increased by naloxone and their other scored behaviors were not affected, the results cannot be attributed to a decrease of general activity. In the low aggression pigeons the acute naloxone treatment selectively stimulated offensive aggression without affecting the other behaviors scored. In these animals, only pecking was the offensive behavior component significantly increased by the drug.

The results suggest that activity of the opioid system is involved in the mediation of the offensive aggression responses induced by food competition in female pigeons. There is evidence supporting the idea that naloxone exerts GABA-antagonistic effects in addition to its potent opioid-antagonistic effects in pigeons and mammals $(6,9)$. A DZPinduced reduction of emotional responses in high aggression pigeons in a similar test situation has been reported to reflect inhibition of an expression of anxiety-like behavior (4). The present finding of a stimulating action of naloxone on the emotional response of high aggression pigeons, therefore, would be an expression of anxiogenesis. This suggests that naloxone has antagonistic effects on GABA-A-BZD receptors $(6,9)$.

It has been reported that naloxone significantly decreased the time spent in aggressive acts in 5,7-DHT-lesioned rats in a modified Vogel's conflict test. Since this effect was prevented by a low inert dose of amobarbital and was reproduced by the partial inverse agonist of BZD receptors, Ro 154513 , it was suggested that the effects of naloxone on aggressive behavior may involve an antagonistic action on GABA-ABZD receptor complexes (6). The present results, however, show that the effect of naloxone on the aggressive behavior of both high and low aggression pigeons exposed to food competition interactions agrees with that described previously for DZP in a similar test situation (4). DZP decreased food competition offensive aggression in high aggression pigeons and increased aggression in low aggression pigeons, as shown here for naloxone. The effects of DZP on aggression were blocked by low doses of flumazenil, suggesting that they may be related to GABA-A-BZD receptor mechanisms in both high and low aggression pigeons (4).

Taken together, these results suggest that the emotional response to naloxone is consistent with a GABA antagonistic action but also suggest that this might not be the case for the effect of naloxone on food competition offensive aggression in female pigeons.

As previously reported for brain 5-HT manipulation (1-3) and GABA-A-BZD receptor manipulation (4), the effect of opiate receptor manipulation on food competition aggression in pigeons reported here was also related to the level of spontaneous aggression displayed prior to treatment.

\section{Acknowledgments}

The authors wish to thank Dr. Fabio Sacerdote (Instituto de Histología y Embriología, Universidad Nacional de Cyo) for a critical reading of the text and Mrs. María Patricia Zapata (Area of Pharmacology, CONICET, Universidad Nacional de Cuyo) for assistance with the preparation of the manuscript. 


\section{References}

1. Fachinelli C, Sargo S, Bataller R \& Rodríguez Echandía EL (1989). Effect of 5-HTP and ketanserine on the aggressive reaction induced by food competition in dominant and submissive pigeons (Columba livia). Behavioural Brain Research, 35: 265-270.

2. Fachinelli C, Ison M \& Rodríguez Echandía EL (1996). Effect of subchronic and chronic exposure to 5-hydroxytryptophan (5-HTP) on the aggressive behavior induced by food competition in undernourished dominant and submissive pigeons (Columba livia). Behavioural Brain Research, 75: 113-118.

3. Ison M, Fachinelli C \& Rodríguez Echandía EL (1996). Effect of the icv injection of 5,7-di-hydroxytryptamine on the aggressibe behavior of dominant and submissive pigeons (Columba livia). Pharmacology, Biochemistry and Behavior, 53: 951-955.

4. Fachinelli C, Ison M \& Rodríguez Echandía EL (2003). Effects of diazepam and flumazenil on food competition in high- and lowaggression pigeons. Pharmacology, Biochemistry and Behavior, 74: 765-770.

5. Riddle MA, Bernstein GA, Cook EH, Leonard HL, March JS \&
Swanson JM (1999). Anxiolytics, adrenergic agents and naltrexone. Journal of the American Academy of Child and Adolescent Psychiatry, 38: 546-556.

6. Soderpalm B \& Svensson AI (1999). Naloxone reverses disinhibitory/ aggressive behavior in 5,7-DHT-lesioned rats; involvement of GABA (A) receptor blockade. Neuropharmacology, 38: 1851-1859.

7. Kudriavtseva NN, Dolgov W, Avgustinovich DF, Alekseenko OV, Lipina TV \& Koriakina LA (2001). Modifying effect of the repeated experience of agonistic confrontations on effect of naltrexone in male mice. Fiziologicheskii Zhurnal SSSR Imeni IM Sechenova, 87: 227-238.

8. Halas E, Reynolds G, Rowe M, Heinrich M \& Pirc M (1977). Comparison of frequency, intensity and duration of aggressive responses in rats. Physiology and Behavior, 18: 975-977.

9. Carter RB \& Leander JD (1984). Comparison of the effects of naloxone and piroxetin on schedule controlled responding in the pigeon: possible GABA-antagonistic effects of naloxone. Journal of Pharmacology and Experimental Therapeutics, 230: 40-46. 